\title{
Modeling biomass char gasification kinetics for improving prediction of carbon conversion in a fluidized bed gasifier
}

\author{
Jason Kramb ${ }^{\mathrm{a}}$, Jukka Konttinen ${ }^{\mathrm{a}}$, Alberto Gómez-Barea ${ }^{\mathrm{b}}$, Antero Moilanen ${ }^{\mathrm{c}}$, Kentaro Umeki ${ }^{\mathrm{d}}$ \\ ${ }^{a}$ Department of Chemistry, Renewable Energy Programme, University of Jyväskylä, PO Box 35, FI-40014 Jyväskylä, Finland \\ ${ }^{b}$ Bioenergy Group, Chemical and Environmental Engineering Department, Escuela Superior de Ingenieros, University of Seville, Camino de los Descubrimientos \\ $s / n, 41092$ Seville, Spain \\ ${ }^{c}$ VTT Technical Research Centre of Finland, P.O. Box 1000, 02044 VTT, Finland \\ ${ }^{d}$ Division of Energy Science, Department of Engineering Sciences and Mathematics, Luleå University of Technology, 97187 Luleå, Sweden
}

\begin{abstract}
Gasification of biomass in a fluidized bed (FB) was modeled based on kinetic data obtained from previously conducted thermogravimetic analysis. The thermogravimetric analysis experiments were designed to closely resemble conditions in a real FB gasifier by using high sample heating rates, in situ devolatilization and gas atmospheres of $\mathrm{H}_{2} \mathrm{O} / \mathrm{H}_{2}$ and $\mathrm{CO}_{2} / \mathrm{CO}$ mixtures. Several char kinetic models were evaluated based on their ability to predict char conversion based on the thermogravimetric data. A modified version of the random pore model was shown to provide good fitting of the char reactivity and suitability for use in a reactor model. An updated FB reactor model which incorporates the newly developed char kinetic expression and a submodel for the estimation of char residence time is presented and results from simulations were compared against pilot scale gasification data of pine sawdust. The reactor model showed good ability for predicting char conversion and product gas composition.
\end{abstract}

Keywords: biomass, gasification, reaction kinetics, modeling, fluidized bed

\section{Introduction}

Gasification of biomass has become a topic of increasing interest as a potentially renewable method of electricity, heat and liquid fuel production. The gasification process can be divided into a number of steps, of which char gasification is often the slowest. As a result, char gasification tends to represent a rate controlling step of the overall thermo-chemical conversion process. Char can contain $25 \%$ of the energy content of the biomass fuel [1] and the total char conversion can significantly influence the composition of the product gas as well as the overall efficiency of the gasification process. As a result, accurate prediction of char conversion is a key factor to optimize a biomass gasifier.

Mathematical models for fluidized bed gasification (FBG) can be used in all stages of the gasifier design and operation. The models can vary significantly in terms of complexity and scope, where the two extremes are often considered to be thermodynamic equilibrium models for simplicity and computation fluid dynamical models for complexity [2]. For all modeling approaches obtaining experimental data for model validation is a widely acknowledged challenge.

This work presents a method for predicting the reactivity of biomass char as a function of conversion, temperature and pressure based on experimental data obtained from dedicated thermogravimetric analysis, where operating conditions are applied to closely resemble conditions in a FBG. Various char reactiv-

Email address: jason.kramb@jyu.fi (Jason Kramb) ity models were examined for their ability to predict the experimental conversion rate and suitability for use in a FBG model. One of these char reactivity models was implemented into a FBG model and the modeling results were compared against measured char conversion and product gas composition from a pilot scale gasifier. The focus of the model is to examine the effects of char reactivity on the performance of FBGs. The model is intentionally simple in that the required inputs are easily obtained experimental characterization of the fuel and basic reactor operating conditions.

\section{Theory and methods}

This section presents the approach followed in this work to model a FBG from thermogravimetric analysis (TGA) measurements. Four different aspects are discussed: (i) definitions of char reactivity and reaction rates; (ii) how to calculate these quantities from TGA measurements in which the whole conversion of the sample occurs, including devolatilization and char gasification; (iii) selection of a model to represent the effects of temperature, gas composition and carbon conversion in the form of a kinetics equation; (iv) development of a FBG model where the char reactivity model is implemented together with devolatilization and reactor considerations (e.g. input flow rate of biomass fuel, ash bed inventory, reactor size).

\subsection{Definitions}

Char conversion of a fuel sample being converted at uniform and constant temperature and gas composition is defined 


\section{Nomenclature}

\section{Abbreviations}

DAF dry ash-free fuel

FB fluidized bed

FBG fluidized bed gasifier

HRPM hybrid random pore model

MRPM modified random pore model

PPW proposed in present work

RPM random pore model

TGA thermogravimetric analysis

UCM uniform conversion model

\section{Symbols}

$\alpha \quad$ kinetic parameter for hybrid models [-]

$\psi \quad$ random pore model surface parameter [-]

$\tau \quad$ char residence time [s]

$\tau_{2} \quad$ time constant for bottom ash removal [s]

$\tau_{3} \quad$ time constant for fly ash removal [s]

$\tau_{R} \quad$ char conversion time [s]

$\xi \quad$ catalytic deactivation coefficient [-]

$c \quad$ modified random pore model parameter [-]

$E \quad$ activation energy $[\mathrm{J} / \mathrm{mol}]$

$k_{0} \quad$ frequency factor for Arrhenius terms [1/s]

$k_{3} \quad$ Arrhenius term of $K_{r}[1 / \mathrm{s}]$

$K_{r} \quad$ kinetic coefficient $[1 / \mathrm{s}]$

$k_{1 b} \quad$ Arrhenius term of $K_{r}[1 / \mathrm{s}]$

$k_{1 f} \quad$ Arrhenius term of $K_{r}[1 / \mathrm{s}]$ $k_{c c g, 1} \quad$ three parallel reaction model rate coefficient [1/s]

$k_{c c g, 2}$ three parallel reaction model rate coefficient [1/s]

$k_{n c g} \quad$ three parallel reaction model rate coefficient [1/s]

$m_{0} \quad$ initial char mass $[\mathrm{g}]$

$N \quad$ number of reactor sections in FBG model [-]

$n_{c, f i x} \quad$ char carbon flow from devolatilization stage [mols/s]

$N_{C, t o t}$ total carbon inventory in the reactor bed [mol]

$n_{\mathrm{CO}_{2}, e q,(i)}$ equilibrium adjusted $\mathrm{CO}_{2}$ flow leaving reactor section $i[\mathrm{~mol} / \mathrm{s}]$

$n_{\mathrm{H}_{2} \mathrm{O}, e q,(i)}$ equilibrium adjusted steam flow leaving reactor section $i[\mathrm{~mol} / \mathrm{s}]$

$p \quad$ modified random pore model parameter [-]

$p_{i} \quad$ partial pressure of gas $i$ [bar]

$r \quad$ conversion rate $[1 / \mathrm{s}]$

$r^{\prime \prime} \quad$ instantaneous reaction rate $[1 / \mathrm{s}]$

$r_{(i)}^{*} \quad$ apparent instantaneous reactivity in $i$ th section of gasifier model [1/s]

$T$ temperature $\left[{ }^{\circ} \mathrm{C}\right]$

$W_{b, t o t} \quad$ total bed inventory $[\mathrm{kg}]$

$w_{c, c h, b}$ weight percentage of carbon in char in the bed [-]

$w_{c, c h, d}$ weight percentage of carbon in char from devolatilization [-]

$X_{c h} \quad$ char conversion [-]

$X_{c} \quad$ overall fuel carbon conversion [-]

$X_{g,(i)} \quad$ fractional molar conversion of reactant gas in section $i$ of FBG reactor model [-] as,

$$
X_{c h}=\frac{m_{0}-m_{t}}{m_{0}}
$$

and the instantaneous reactivity is calculated by normalizing the conversion rate by the mass of the sample at time $t$,

$$
r "=-\frac{1}{m_{t}} \frac{d m_{t}}{d t}=\frac{1}{1-X_{c h}} \frac{d X_{c h}}{d t} .
$$

\subsection{Measuring char reactivity for FBG from thermogravimet-} ric measurements

As the purpose of this work is to model gasification of biomass in FBGs, the TGA experiments were designed to mimic the conditions of those gasifiers as closely as possible. The experimental setup and data used in the present work has been described in detail elsewhere [3]. In the experiments the sample is lowered into the preheated reactor chamber causing devolatilization and gasification reactions to begin immediately. This way of operation closely simulates the char generation in a FBG in a number of key ways: high heating rates during devolatilization, devolatilization occurs in the presence of the gasification agent, and, most importantly, the sample is not cooled between devolatilization and char gasification.

The tests were carried out in isothermal conditions on pine sawdust samples at $750^{\circ} \mathrm{C}$ and $850^{\circ} \mathrm{C}$ using atmospheres con- 
taining mixtures of either $\mathrm{H}_{2} \mathrm{O} / \mathrm{H}_{2}$ or $\mathrm{CO}_{2} / \mathrm{CO}$. Proximate and ultimate analysis of the fuel samples have been published previously by Moilanen and Saviharju [4]. The volume fraction of each gas component in the atmosphere during each TGA test was varied to observe the inhibiting effects of $\mathrm{H}_{2}$ and $\mathrm{CO}$ on the char reactivity. Table 1 summarizes the operating conditions for the TGA tests [4].

While this setup more accurately resembles a fuel particle being injected into a hot fluidized bed, it adds the complication of separating the devolatilization and gasification stages in order to correctly model only the char gasification. The approach used in this work to define the initial char conversion is based on the method proposed by Umeki et al. [5] who established clearly how to obtain char conversion versus time data from similar TGA data where the overall fuel conversion takes place. For all TGA experiments the starting point of gasification was between 60 and 120 seconds from when the sample was lowered into the reactor chamber.

\subsection{Modeling of char reactivity}

A variety of approaches have been proposed to describe the gasification reactivity of biomass char in the past [6][2]. The variation of conversion rate with temperature, gas composition and carbon conversion can be written in the general form as

$$
d X_{c h} / d t=f\left(T, p_{i}, X_{c h}\right)
$$

where $T$ is the temperature at which the conversion occurs and $p_{i}$ is the partial pressure of gas species $i$. Most often in char gasification reactivity studies, it is assumed that the effects of operating conditions and char conversion can be separated in a convenient form to fit the measurements, giving the following expression to represent the conversion rate

$$
d X_{c h} / d t=K_{r}\left(T, p_{i}\right) F\left(X_{c h}\right)
$$

where $K_{r}\left(T, p_{i}\right)$ is the kinetic coefficient and the second term, $F\left(X_{c h}\right)$, is the term which expresses the reactivity dependence on conversion and can take a number of different forms. Both terms, $K_{r}\left(T, p_{i}\right)$ and $F\left(X_{c h}\right)$, may contain parameters to be fit by measurements [6].

Experimental representation of the function $f$ in Equation 4 is difficult and there is not yet a general model where $f$ is explicitly obtained. Despite this, there are some models that have tried to find such an expression for certain operating conditions. A model of this type, the three parallel reaction model [5], is briefly analyzed below. In contrast, a variety of expressions have been presented in literature to fit both $K_{r}\left(T, p_{i}\right)$ and $F\left(X_{c h}\right)$ to measurements. Some of these models are based on fundamental description of the processes taken at the char surface and others by empirical expressions. Table 2 shows the conversion rate equations that were considered in this work for modeling char gasification reactivity of pine sawdust.

The Langmuir-Hinshelwood kinetic model has been widely used to model the kinetic coefficient, $K_{r}\left(T, p_{i}\right)$, in gasification processes. Although there remains some criticism to this kinetic model [7], the Langmuir-Hinshelwood model has been widely used with success to model measurements in char reactivity [8], and so has been chosen to represent $K_{r}\left(T, p_{i}\right)$ in this study. In previous work [9] Equations 6 and 7, as described by Barrio [10], have been used for the kinetic coefficient for $\mathrm{CO}_{2}$ and steam gasification:

$$
K_{r-\mathrm{CO}_{2}}=\frac{k_{1 f} p_{\mathrm{CO}_{2}}}{1+\frac{k_{1 f}}{k_{3}} p_{C O_{2}}+\frac{k_{1 b}}{k_{3}} p_{C O}}
$$

and

$$
K_{r-H_{2} O}=\frac{k_{1 f} p_{H_{2} O}}{1+\frac{k_{1 f}}{k_{3}} p_{H_{2} O}+\frac{k_{1 b}}{k_{3}} p_{H_{2}}} .
$$

These equations account for the inhibiting effects of $\mathrm{CO}$ and $\mathrm{H}_{2}$ on the gasification reaction rate and show a good ability to predict the measured reactivities. The kinetic parameters $\left(k_{1 f}\right.$, $k_{1 b}, k_{3}$ ) have the form of the Arrhenius equation,

$$
k=k_{0} \exp (-E / R T),
$$

where $k_{0}$ is the frequency factor and $\mathrm{E}$ the activation energy. Figure 1 shows the predicted reactivities from Equations 6 and 7 with the measured averaged reactivity (averaged from approximately $30-80 \%$ char conversion) at $750^{\circ} \mathrm{C}$ and $850^{\circ} \mathrm{C}$ for both steam and $\mathrm{CO}_{2}$ gasification [9]. Throughout this work it can be assumed that all kinetic coefficients, $K_{r}$, follow Equations 6 and 7 for $\mathrm{CO}_{2}$ and $\mathrm{H}_{2} \mathrm{O}$ gasification respectively.
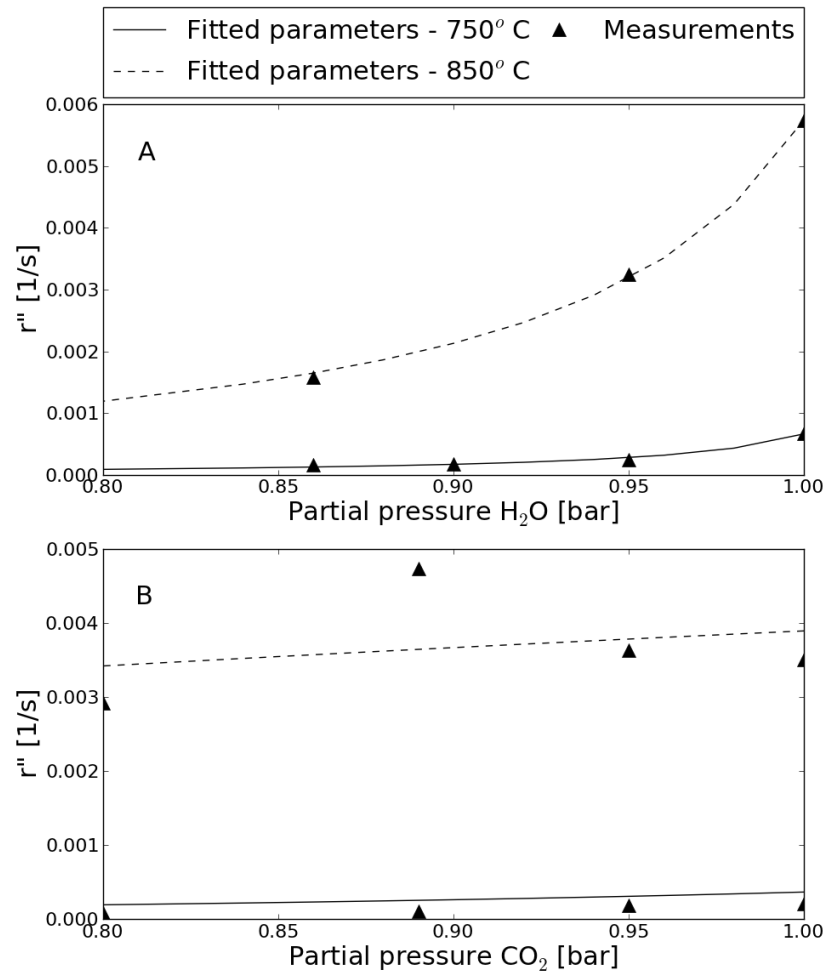

Figure 1: Average reactivity values for steam (A) and $\mathrm{CO}_{2}(\mathrm{~B})$ gasification from TGA data and the reactivities calculated from fitted kinetic parameters using Eq 7 and Eq 6 [9].

Regarding the variation of reactivity with conversion, represented by $F\left(X_{c h}\right)$, five reactivity models (see Table 2) are 
Table 1: TGA testing conditions of pine sawdust used for char reactivity modeling showing reactor temperature and gas partial pressures [4].

\begin{tabular}{|c|c|c|c|c|c|}
\hline \multicolumn{3}{|c|}{$\mathrm{CO}_{2}$ gasification } & \multicolumn{3}{|c|}{$\mathrm{H}_{2} \mathrm{O}$ gasification } \\
\hline Temperature $\left({ }^{\circ} \mathrm{C}\right)$ & $\mathrm{p}_{\mathrm{CO}_{2}}[$ bars $]$ & $\mathrm{p}_{C O}[$ bars $]$ & Temperature $\left({ }^{\circ} \mathrm{C}\right)$ & $\mathrm{p}_{\mathrm{H}_{2} \mathrm{O}}$ [bars] & $\mathrm{p}_{H_{2}}$ [bars] \\
\hline 750 & 1 & 0 & 750 & 1 & 0 \\
\hline 750 & 0.95 & 0.05 & 750 & 0.95 & 0.05 \\
\hline 750 & 0.89 & 0.11 & 750 & 0.9 & 0.1 \\
\hline 750 & 0.8 & 0.2 & 750 & 0.86 & 0.14 \\
\hline 850 & 1 & 0 & 850 & 1 & 0 \\
\hline 850 & 0.95 & 0.05 & 850 & 0.95 & 0.05 \\
\hline 850 & 0.89 & 0.11 & 850 & 0.86 & 0.14 \\
\hline 850 & 0.8 & 0.2 & & & \\
\hline
\end{tabular}

examined in this work using the TGA experimental data for sawdust: the uniform conversion model (UCM), random pore model (RPM), modified random pore model (MRPM), and a 'hybrid' version of the RPM (HRPM) and MRPM (HMRPM) which attempts to better model the higher conversion rate which is observed at low conversion levels.

The three parallel reaction model was developed by Umeki et al. [5] to describe the catalytic effects of ash in biomass gasification and is an example of a conversion model in the form of Equation 4. The model can be expressed as

$$
r=k_{c c g, 1} \exp \left(-\xi X_{c h}^{2}\right)+k_{n c g}\left(1-X_{c h}\right)+k_{c c g, 2},
$$

where $\xi$ is a structural parameter for the fuel type and $k_{c c g, 1}$, $k_{n c g}$ and $k_{c c g, 2}$ are kinetic coefficients. The model divides the char gasification into three stages: a regime of high reactivity where catalyst deactivation occurs, a slower first-order kinetic regime in which non-catalytic gasification takes place, and a zeroth order kinetic regime where the catalyst is again influential. Figure 2 shows the model prediction for the conversion rate of four sets of TGA reactivity data from sawdust. While this parallel reaction model can accurately predict the reactivity and conversion time of biomass char for $\mathrm{CO}_{2}$ gasification, the kinetic coefficients $k_{c c g, 1}, k_{n c g}$, and $k_{c c g, 2}$ have complex pressure and temperature dependence. The correlation factor $\xi$ has also been shown to have dependence on temperature. As a result, the three parallel reaction model is currently limited to predicting conversion rates only at the temperature and pressure conditions of the experimental data. This limitation makes this model currently unsuitable for use in the carbon conversion predictor presented below.

The random pore model developed by Bhatia and Perlmutter [11][12] attempts to describe the changes in the pore structure during the conversion of the fuel. It has been widely used for oxidation and gasification of numerous fuels. Zhang et. al. [13] created a modified random pore model (MRPM) in order to fit conversion data of biomass chars which showed a maximum in the conversion rate at high char conversion. This was done by adding a new conversion term to the original RPM, as shown in Equation 12. The two dimensionless parameters introduced in the MRPM were shown to be correlated with the amount of active potassium in the fuel sample.

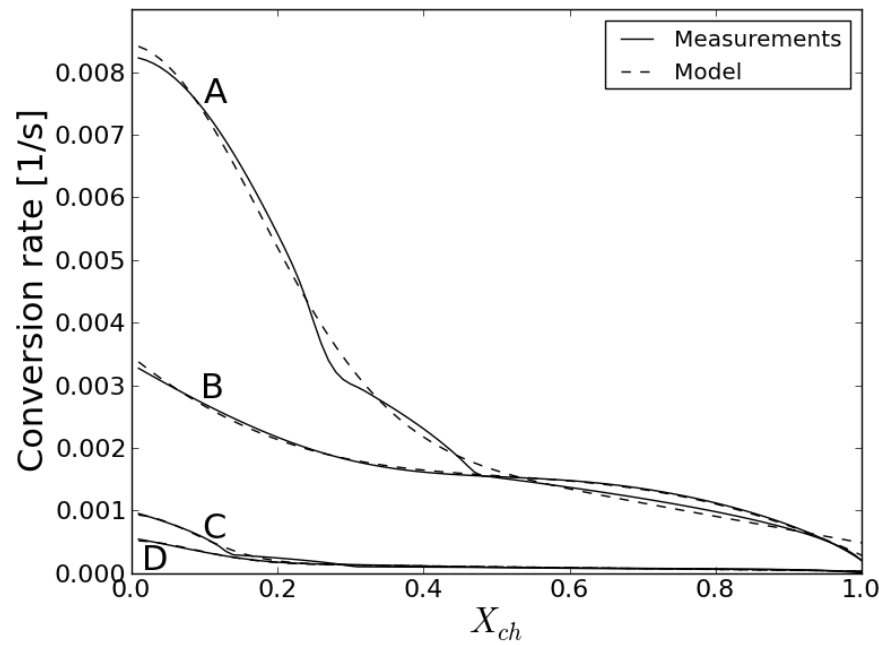

Figure 2: Four sets of TGA conversion rate data with corresponding predictions from the three parallel reaction model developed by Umeki et. al [5], shown in Equation 9. A $-850^{\circ} \mathrm{C}, 1$ bar $\mathrm{CO}_{2}$; B $-850^{\circ} \mathrm{C}, 0.8$ bar $\mathrm{CO}_{2}, 0.2$ bar $\mathrm{CO}$; $\mathrm{C}$ $780^{\circ} \mathrm{C}, 1$ bar $\mathrm{CO}_{2} ; \mathrm{D}-780^{\circ} \mathrm{C}, 0.95$ bar $\mathrm{CO}_{2}, 0.05$ bar $\mathrm{CO}$

Both the RPM and MRPM showed good ability to fit the measured conversion rate curves of pine sawdust for high conversion $\left(X_{c h}>0.4\right)$ as seen in Figures 3 and 4 which show measured conversion rates for two TGA test conditions and the predicted conversion rates for various models. The TGA measurements typically show slightly higher conversion rates at the end of char conversion $\left(X_{c h}>0.8\right)$ than predicted by the RPM, but this is not as pronounced as what was observed by Zhang et al. [13] and as a result the improvements offered by the MRPM in modeling the $d X_{c h} / d t$ curve is less significant. The deviation of the models from the measured data at low char conversion is attributed to the char generation conditions. In previous works where the random pore model or modified random pore model have been used, the char samples were prepared before gasification, usually by heating at a controlled rate in a nitrogen atmosphere [13][15]. This differs significantly from the in situ char formation process described in Section 2.2 and used in this work. The higher than expected char reactivity at low conversion may be explained by small amounts of remaining volatiles being released through ongoing devolatilization, as well as the 
Table 2: Char conversion equations considered for modeling TGA data. All equations were used for both $\mathrm{CO}_{2}$ and steam gasification. As mentioned, the kinetic coefficient terms, $\mathrm{K}_{r}$, follow Equations 6 and 7 for $\mathrm{CO}_{2}$ and steam gasification respectively. Acronyms: UCM - Uniform conversion model, RPM - Random pore model, MRPM - Modified random pore model, HRPM - Hybrid random pore model, HMPRM - Hybrid modified random pore model, PPW - Proposed in the present work.

\begin{tabular}{llrlr}
\hline Model & $\mathrm{f}\left(\mathrm{T}, \mathrm{p}_{i}, \mathrm{X}_{c h}\right)=\mathrm{K}_{r}\left(\mathrm{~T}, \mathrm{p}_{i}\right) \mathrm{F}\left(\mathrm{X}_{c h}\right)$ & Eq. & Model parameters & Reference \\
\hline UCM & $K_{r}\left(1-X_{c h}\right)$ & $(10)$ & $K_{r}$ & {$[14]$} \\
RPM & $K_{r}\left(1-X_{c h}\right) \sqrt{1-\psi \log \left(1-X_{c h}\right)}$ & $(11)$ & $K_{r}, \psi$ \\
MRPM & $K_{r}\left(1-X_{c h}\right) \sqrt{1-\psi \log \left(1-X_{c h}\right)}\left(1+\left(c X_{c h}\right)^{p}\right)$ & $(12)$ & $K_{r}, \psi, c, p$ \\
HRPM & $K_{r}\left(\alpha \exp \left(-\xi X_{c h}{ }^{2}\right)+\left(1-X_{c h}\right) \sqrt{1-\psi \log \left(1-X_{c h}\right)}\right)$ & $(13)$ & $K_{r}, \alpha, \xi, \psi$ \\
HMRPM & $K_{r}\left(\alpha \exp \left(-\xi X_{c h}{ }^{2}\right)+\left(1-X_{c h}\right) \sqrt{1-\psi \log \left(1-X_{c h}\right)}\left(1+\left(c X_{c h}\right)^{p}\right)\right)$ & $(14)$ & $K_{r}, \alpha, \xi, \psi, c, p$ & PPW \\
& & & PPW
\end{tabular}

dependence of char properties and reactivity on devolatilization conditions. It has been shown for several types of biomass that higher pyrolysis heating rates will generally lead to higher reactivities [16]. This section of the conversion curve also corresponds with the regime describing catalytic gasification with deactivation of the catalyst in the three parallel reaction model and this fact was used to develop the present version of a char kinetic model as discussed below.

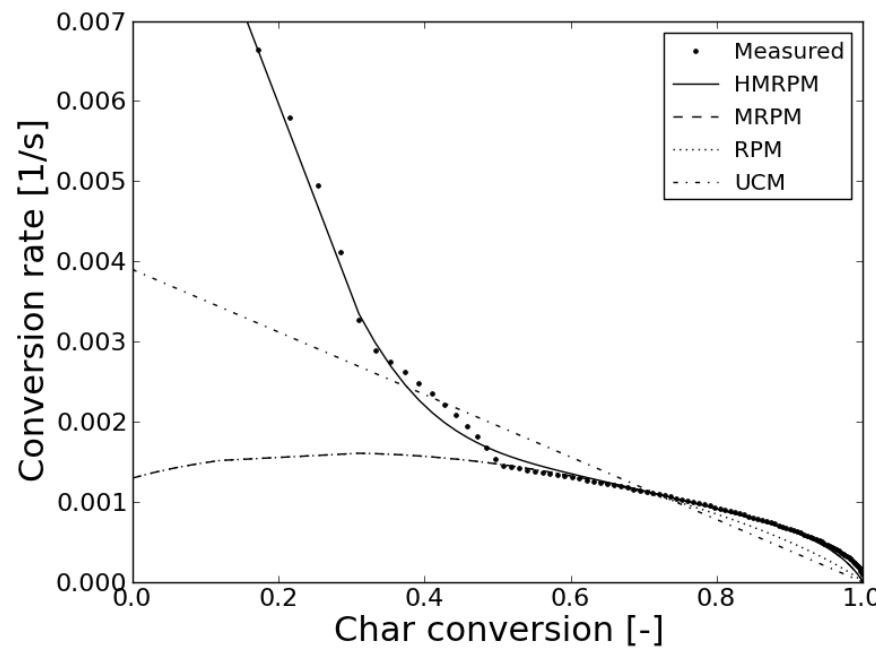

Figure 3: Measured char conversion rate from $\mathrm{CO}_{2}$ gasification at $850^{\circ} \mathrm{C}, 1$ bar $\mathrm{CO}_{2}$ and the predicted conversion rates from the UCM, RPM, MRPM, and HMRPM. The RPM and MRPM are identical for $0<\mathrm{X}_{c h}<0.6$, after which the RPM model begins to show lower conversion rate than the MRPM.

In order to improve the ability of the modified random pore model to predict the conversion rate of the char as measured in

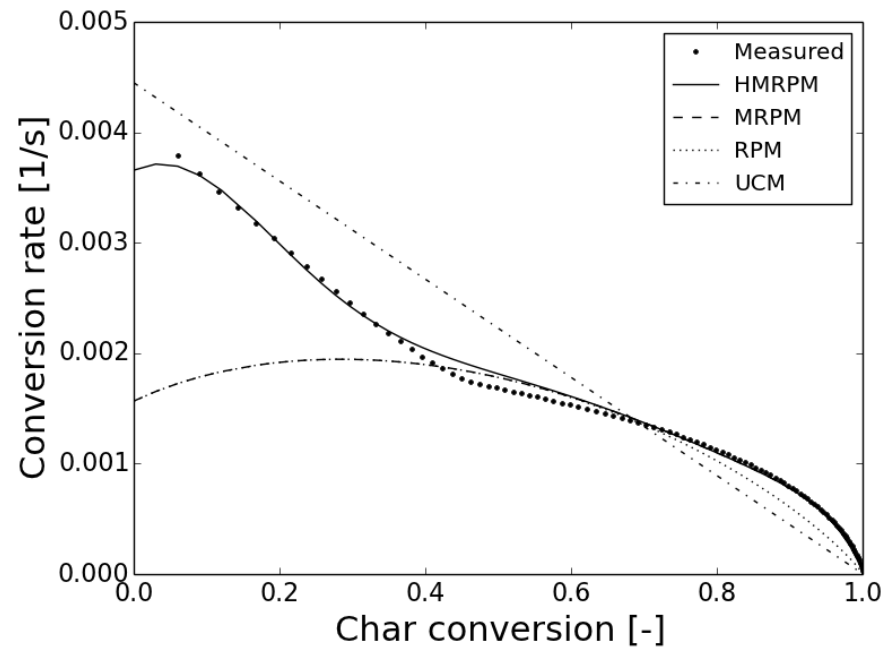

Figure 4: Measured char conversion rate from steam gasification at $850^{\circ} \mathrm{C}$, 0.95 bar $\mathrm{H}_{2} \mathrm{O}, 0.05$ bar $\mathrm{H}_{2}$ and the predicted conversion rates from the UCM, RPM, MRPM, and HMRPM. The RPM and MRPM are identical for $0<\mathrm{X}_{c h}<$ 0.7 , after which the RPM model begins to show lower conversion rate than the MRPM.

in Equation 9 and a second period following either the RPM or MRPM. In order to separate the kinetic and structural terms of the conversion rate equation according to Equation 5, it was assumed that the kinetic coefficient $\mathrm{k}_{c c g, 1}$ was proportional to the kinetic coefficient of the RPM/RMPRM $\left(k_{c c g, 1}=\alpha K_{r}\right)$ and that the correlation factor $\xi$ was not dependent on temperature. These hybrid models are shown by Equations 13 and 14 in Table 2 .

\subsection{Carbon conversion predictor model}

An improved carbon conversion predictor has been developed to model biomass gasification in a fluidized bed. The original model has been described previously [17][9]. The goal of the model is to limit the required inputs to easily obtained data 
on the fuel properties and reactor parameters while providing an accurate estimate of the overall carbon conversion and product gas composition. A schematic outline of the model is shown in Figure 5. The basic input to the model consists of proximate and ultimate analysis of the fuel as well as the char reactivity data from the TGA measurements. The reactor feed rates for air, steam and the fuel and the reactor operating conditions are also required. The model contains a simple devolatilization submodel which assumes this stage (releasing of volatiles from the fuel particle) to happen instantly when the fuel particle is injected into the reactor. The products of the devolatilization submodel, char and gas streams, are calculated based on thermochemical equilibrium which is explained in more detail elsewhere [9].

Figure 6 shows the basic calculation procedure involved in the FBG model. The fluidized bed is divided into $\mathrm{N}$ vertical sections which are modeled as ideally stirred reactors. For each vertical section the char conversion and product gas composition is calculated and the gas composition leaving section $i$ is used for calculating the char reactions of section $i+1$. In order to be consistent with previous results from the carbon conversion predictor [9], $\mathrm{N}=8$ was used in this work. This value was chosen in the original model because when the number of vertical sections of the gasifier model is greater than eight the model results become sufficiently independent of this parameter.

In addition, the updated reactor model incorporates a new submodel to calculate the char residence time, $\tau$, which was not calculated in the previous version of the model [9] but assumed to equal the char conversion time, $\tau_{R}$. The equations developed by Gómez-Barea and Leckner [18] were implemented in the new version of the FBG model, which relate $\tau$ with the mass fraction of carbon in the char of the reactor bed, $\mathrm{w}_{c, c h, b}$, and the char conversion attained in the reactor, $X_{c h}$. These are shown in Equations 15, 16 and 17 respectively:

$$
\tau=\frac{1}{\left(1 / \tau_{2}+1 / \tau_{3}\right)}\left(1-\frac{w_{c, c h, d} / \tau_{R}}{\left(1 / \tau_{2}+1 / \tau_{3}+1 / \tau_{R}\right.}\right),
$$

$$
w_{c, c h, b}=\frac{\left(1 / \tau_{2}+1 / \tau_{3}\right) w_{c, c h, d}}{1 / \tau_{2}+1 / \tau_{3}+\left(1-w_{c, c h, d}\right) / \tau_{R}},
$$

and

$$
X_{c h}=1-\frac{w_{c, c h, b}}{w_{c, c h, d}}\left(\frac{\tau}{\tau_{2}}+\frac{\tau}{\tau_{3}}\right),
$$

where $\tau_{2}$ is the time constant for bottom ash removal, $\tau_{3}$ is the time constant for fly ash removal, $\mathrm{w}_{c, c h, d}$ is the mass fraction of carbon in char from the devolatilization submodel and $\tau_{R}$ is the char conversion time which is calculated as

$$
\begin{array}{r}
\tau_{R}=\int_{0}^{X_{c h}} 1 /\left(K _ { r } \left(\alpha \exp \left(-\xi X_{c h}^{2}\right)\right.\right. \\
\left.\left.+\left(1-X_{c h}\right) \sqrt{1-\psi \log \left(1-X_{c h}\right)}\right)\right) d X_{c h}
\end{array}
$$

according to the proposed HRPM shown in Equation 13. This method allows for the accounting of carbon lost through bottom and fly ash on carbon conversion and residence time, which was missing in the original model design. Due to the new conversion dependence of the reaction time an initial guess for $X_{c h}$ must be made at the beginning of the calculation process. These calculations are then iterated until the values of $\tau$ and $X_{c h}$ converge.

The balance equation for the carbon consumed in the steam and $\mathrm{CO}_{2}$ gasification reactions in the $i$ th section of the reactor are given as,

$$
\frac{N_{C, t o t}}{N} r_{H_{2} O,(i)}^{*}=n_{H_{2} O, e q(i-1)} X_{g, H_{2} O,(i)},
$$

and

$$
\frac{N_{C, t o t}}{N} r_{\mathrm{CO}_{2},(i)}^{*}=n_{\mathrm{CO}_{2}, e q(i-1)} X_{g, \mathrm{CO}_{2},(i)},
$$

where $N_{C, t o t}$ is the total carbon inventory in the reactor bed, $r_{\mathrm{H}_{2} \mathrm{O} \text {,(i) }}^{*}$ and $r_{\mathrm{CO}_{2},(i)}^{*}$ are the effective char reactivities in the $i$ th section of the reactor, $n_{\mathrm{H}_{2} \mathrm{O} \text {,eq,(i-1) }}$ and $n_{\mathrm{CO}_{2}, e q,(i-1)}$ are the flows of steam and $\mathrm{CO}_{2}$ from the previous reactor section, and finally $X_{g, H_{2} O,(i)}$ and $X_{g, C_{2},(i)}$ are the fractional molar conversion of the reactant gases. The carbon inventory, $N_{c, t o t}$, and $w_{c, c h, b}$ are related by the total bed inventory, $W_{b, t o t}$, which must be supplied as a model input. The effective reactivities, $r_{\mathrm{H}_{2} \mathrm{O},(i)}^{*}$ and $r_{\mathrm{CO}_{2},(i)}^{*}$, are assumed to be of the form $r^{*}=\beta r$ " ${ }_{a v g}$ where $r{ }^{\prime}{ }_{\text {avg }}$ is the averaged reactivity from the beginning of char conversion to $X_{c h}$ as calculated in Equation 17. The coefficient $\beta$ is found by the carbon balance relation,

$$
X_{c h} n_{c, f i x}=N_{c, t o t}\left(r{ }_{H_{2} O, a v g}+r{ }_{C O_{2}, a v g}\right) \beta
$$

where $n_{c, f i x}$ is the carbon flow from the devolatilization stage. It can then be shown that

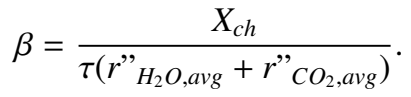

The requirement to maintain simplicity in the carbon conversion predictor has imposed some limitations in the current FBG model. First, the temperature of the reactor is a required input to the model, rather than calculated through an energy balance. Similarly, methane concentration in the product gas is determined from the methane yields determined experimentally during measurements in FBG and is therefore considered an input term. The yield of methane depends on the fuel type and process temperature. For a typical FBG biomass fuels the methane yield is in the range of 50-80 g/kgdaf [19]. Finally, the estimation method for $\tau_{3}$ as a function of operating conditions prevents the use of the model without additional measurements from which the fly ash flow can be estimated. The method used for estimating $\tau_{3}$ for a pilot plant is discussed in Section 3.2.

\section{Results}

\subsection{Reactivity modeling}

The reactivity models from Table 2 were fitted to the measured TGA reactivity data and the ability of each model to accurately predict observed char conversion times was evaluated. For all models the kinetic coefficient $K_{r}\left(T, p_{i}\right)$ was taken as Equation 6 for $\mathrm{CO}_{2}$ gasification and Equation 7 for steam gasification. For each reactivity model a single set of parameters 


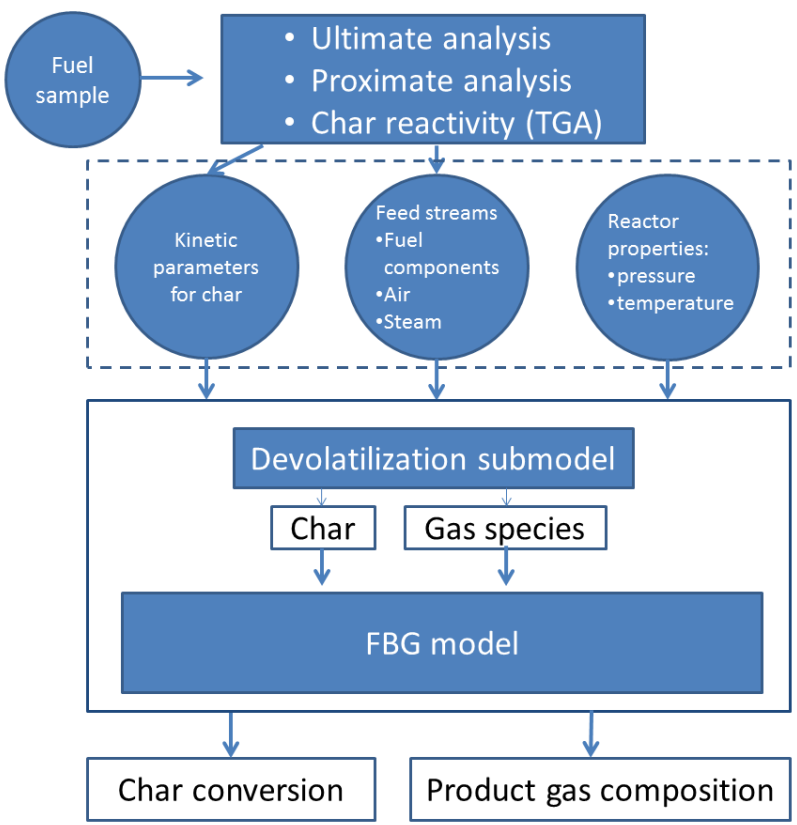

Figure 5: A schematic diagram of the carbon conversion predictor, including model inputs and the outputs of the pyrolysis and FBG submodels.

was found using a least squares method which minimized the error between the model prediction and measured conversion times for all sets of TGA data.

The mean absolute percentage error in predicting experimental conversion times for each model was calculated as,

$$
\epsilon=\frac{1}{N_{j}} \sum_{j=1}^{N_{j}} \frac{1}{N_{j, i}} \sum_{i=1}^{N_{i}}\left|\left(t_{i, j, \text { exp }}-t_{i, j, \text { model }}\right) / t_{i, j, \text { exp }}\right|
$$

where $N_{j}$ is the number of TGA data sets, $N_{j, i}$ is the number of data points in data set $j, t_{i, j, \exp }$ is the experimental conversion time for data point $i$ in set $j$, and $t_{i, j, m o d e l}$ is the model value for point $t_{i, j, \text { exp }}$. The errors are shown in Table 3. The RPM offers significant improvement over the uniform conversion model in all the cases, especially at high conversion. The MRPM improves conversion time prediction slightly compared with the RPM. Using the HRPM and HMRPM decreases the error in predicting conversion time significantly compared with the original RPM and MRPM. The HMRPM gives either minimal or no improvement over the HRPM. The relatively small benefit in using the MRPM over the RPM and the HMRPM over the HRPM is likely this is due to the low ash content, and therefore low potassium content, of the sawdust which would reduce the potential benefits for using the additional terms proposed by Zhang et al. in the MRPM. It was concluded that the HRPM was the best option for modeling the measured char conversion rate as it combines good conversion time predictions with a reasonable amount of fitting parameters. The best fit kinetic and structural parameters in the HRPM for $\mathrm{CO}_{2}$ and $\mathrm{H}_{2} \mathrm{O}$ gasification are shown in Table 4.

The conversion times predicted by the RPM, MRPM, HRPM and UCM are shown with the measured values for twelve sets of

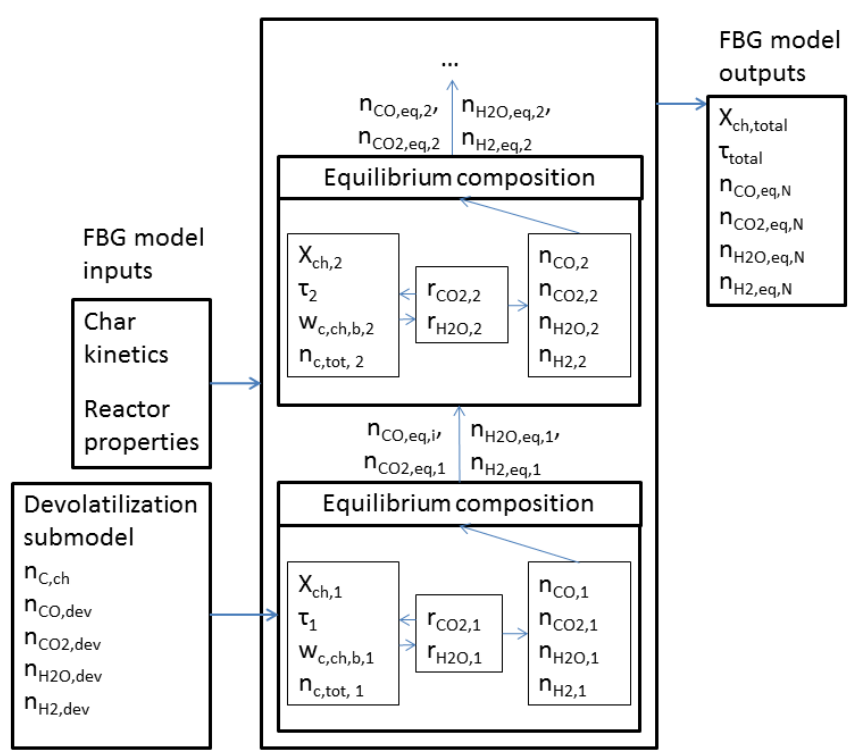

Figure 6: A schematic diagram of the FBG submodel showing the basic calculation procedure for determining char conversion. The final outputs of the model are the overall char conversion, $\mathrm{X}_{c h}$, char residence time, $\tau$, and product gas composition $\left(\mathrm{n}_{C O, e q, N}, \mathrm{n}_{C O 2, e q, N}, \mathrm{n}_{H 2 O, e q, N}, \mathrm{n}_{H 2, e q, N}\right)$. These are taken as the values calculated in the final reactor section.

Table 3: Mean absolute percentage error for estimating conversion times of pine sawdust for five char reactivity models when compared with TGA experiments.

\begin{tabular}{lll}
\hline & $\mathrm{CO}_{2}$ & $\mathrm{H}_{2} \mathrm{O}$ \\
\hline UCM & $82 \%$ & $110 \%$ \\
RPM & $33 \%$ & $28 \%$ \\
MRPM & $28 \%$ & $26 \%$ \\
HRPM & $22 \%$ & $19 \%$ \\
HMRPM & $22 \%$ & $18 \%$ \\
\hline
\end{tabular}

TGA data for both $\mathrm{CO}_{2}$ and $\mathrm{H}_{2} \mathrm{O}$ gasification in Figures 7 and 8 (see Table 1 for all test conditions). It is clear that the UCM often deviates significantly from the measured conversion times, in particular for the $\mathrm{H}_{2} \mathrm{O}$ tests. This was expected as the the UCM in steam gasification has the highest mean absolute percentage error as shown in Table 3. The RPM and MRPM tend to produce very similar conversion time results and while the HRPM improves upon the RPM and MRPM in most test conditions there are examples where the HRPM underperforms. This is to be expected due to the range of test conditions which have been used for the kinetic parameter fitting and it is unlikely that a simple conversion rate expression, such as the HRPM, will be able to produce the most accurate char conversion times in every situation. For this reason the mean absolute percentage error (Table 3) was used in determining the best model for describing the char conversion, indicating the superiority of the HRPM as described above. For both $\mathrm{CO}_{2}$ and $\mathrm{H}_{2} \mathrm{O}$ tests the improvement for using the HRPM was greater at $750^{\circ} \mathrm{C}$ than $850^{\circ} \mathrm{C}$, which shows that accurate modeling of the early stage of char conversion is particularly important at lower tempera- 


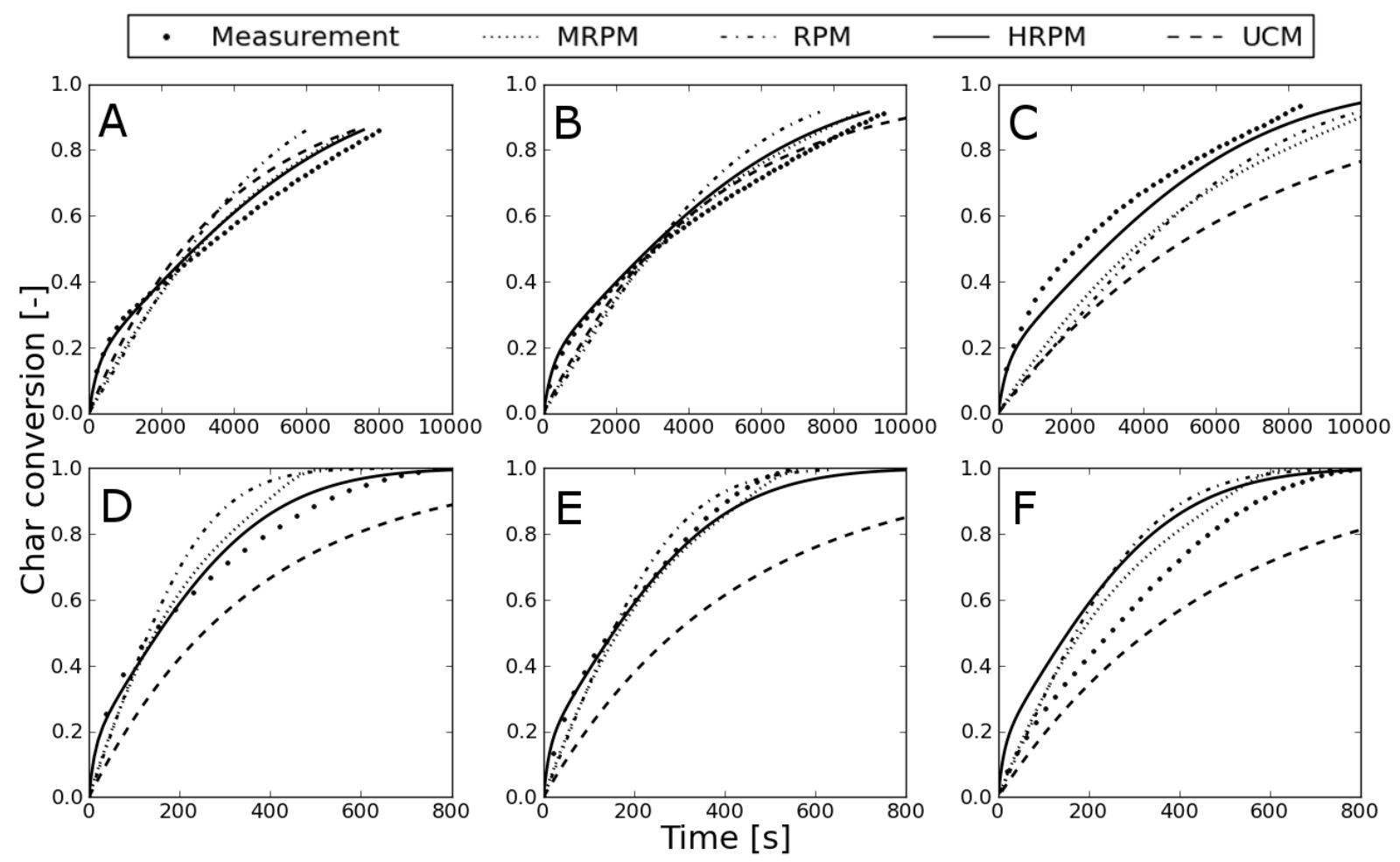

Figure 7: Conversion times for $\mathrm{CO}_{2}$ gasification as predicted by the UCM, the RPM, MRPM and the HRPM. The predicted conversion times are compared with the measured conversion time from the TGA data. A $-750^{\circ} \mathrm{C}, 1$ bar $\mathrm{CO}_{2}$; B $-750^{\circ} \mathrm{C}, 0.95$ bar $\mathrm{CO}_{2}, 0.05$ bar $\mathrm{CO} ; \mathrm{C}-750^{\circ} \mathrm{C}, 0.8$ bar $\mathrm{CO}_{2}, 0.2$ bar $\mathrm{CO} ; \mathrm{D}-850^{\circ} \mathrm{C}, 1$ bar $\mathrm{CO}_{2} ; \mathrm{E}-850^{\circ} \mathrm{C}, 0.89$ bar $\mathrm{CO}_{2}, 0.11$ bar $\mathrm{CO} ; \mathrm{F}-850^{\circ} \mathrm{C}, 0.8$ bar $\mathrm{CO}_{2}, 0.2$ bar $\mathrm{CO}$.

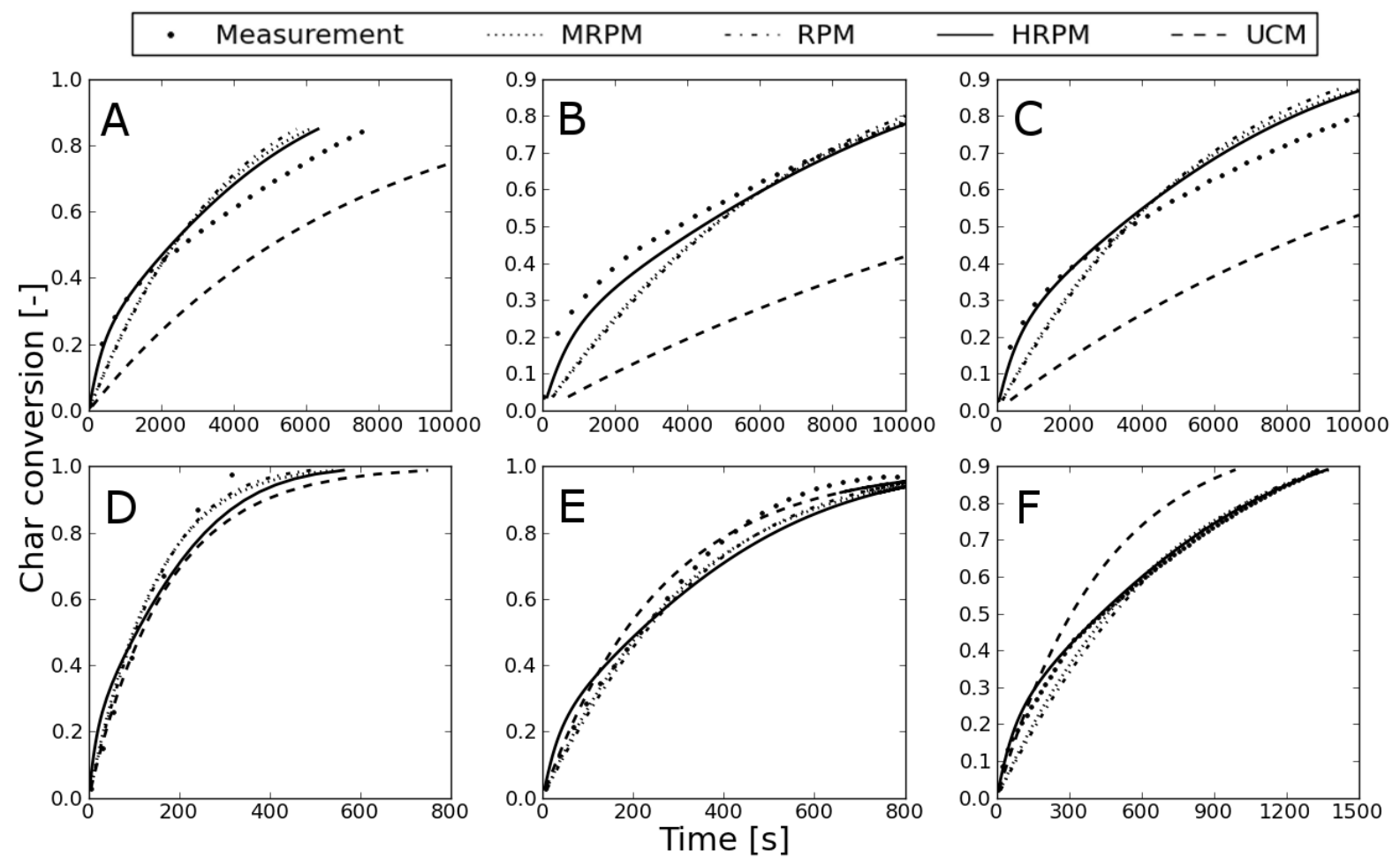

Figure 8: Conversion times for $\mathrm{H}_{2} \mathrm{O}$ gasification as predicted by the UCM, the RPM, MRPM and the HRPM. The predicted conversion times are compared with the measured conversion time from the TGA data. A $-750^{\circ} \mathrm{C}, 0.95$ bar $\mathrm{H}_{2} \mathrm{O}, 0.05 \mathrm{bar} \mathrm{H}_{2} ; \mathrm{B}-750^{\circ} \mathrm{C}, 0.9 \mathrm{bar}_{2} \mathrm{O}, 0.1$ bar $\mathrm{H}_{2} ; \mathrm{C}-750^{\circ} \mathrm{C}, 0.86$ bar $\mathrm{H}_{2} \mathrm{O}, 0.14$ bar $\mathrm{H}_{2}$; D - $850^{\circ} \mathrm{C}, 1$ bar $\mathrm{H}_{2} \mathrm{O} ; \mathrm{E}-850^{\circ} \mathrm{C}, 0.95$ bar $\mathrm{H}_{2} \mathrm{O}, 0.05$ bar $\mathrm{H}_{2} ; \mathrm{F}-850^{\circ} \mathrm{C}, 0.86$ bar $\mathrm{H}_{2} \mathrm{O}, 0.14$ bar $_{2}$. 
Table 4: Arrhenius and structural parameters for $\mathrm{CO}_{2}$ and $\mathrm{H}_{2} \mathrm{O}$ gasification of pine sawdust using the HRPM. The units are $\mathrm{s}^{-1}$ for the frequency factors, $\mathrm{k}_{0}$, and $\mathrm{J} / \mathrm{mol}$ for the activation energies, E.

\begin{tabular}{lrrrrrr}
\hline & $\mathrm{CO}_{2}$ & & & \multicolumn{3}{c}{$\mathrm{H}_{2} \mathrm{O}$} \\
\cline { 1 - 4 } \cline { 5 - 7 } \cline { 5 - 7 } & $\mathbf{k}_{0}$ & $\mathbf{E}$ & & $\mathbf{k}_{0}$ & $\mathbf{E}$ \\
$\mathrm{k}_{1 f}$ & $1.2 \cdot 10^{11}$ & $1.6 \cdot 10^{5}$ & & $\mathrm{k}_{1 f}$ & $1.9 \cdot 10^{7}$ & $2.0 \cdot 10^{5}$ \\
$\mathrm{k}_{1 b}$ & $5.9 \cdot 10^{8}$ & $1.7 \cdot 10^{5}$ & & $\mathrm{k}_{1 b}$ & $2.9 \cdot 10^{10}$ & $2.4 \cdot 10^{5}$ \\
$\mathrm{k}_{3}$ & $2.2 \cdot 10^{10}$ & $2.8 \cdot 10^{5}$ & & $\mathrm{k}_{3}$ & $2.4 \cdot 10^{9}$ & $2.5 \cdot 10^{5}$ \\
& & & & & & \\
$\psi$ & $\alpha$ & $\xi$ & & $\psi$ & $\alpha$ & $\xi$ \\
5.30 & 5.6 & 48 & & 3.9 & 3.8 & 24 \\
\hline
\end{tabular}

tures.

\subsection{Reactor modeling}

The goal of the carbon conversion predictor is to estimate the carbon conversion of a FBG using relatively simple inputs. Results from the improved model were compared to previously published results, which used a more simple reactor model and the UCM to describe char reactivity [9]. The carbon conversion as a function of residence time at $780^{\circ} \mathrm{C}$ is shown in Figure 9 for three versions of the reactor model. Because the original model reported by Konttinen et. al [9] does not have any method for predicting carbon loss through fly ash and the simplicity of UCM kinetics, carbon reaches total conversion at around $\tau=3500 \mathrm{~s}$, as shown by the sold line in Figure 9. The FBG model structure was then left unchanged but the UCM was replaced with the HRPM kinetic model developed in this work. The results from this is shown by the dotted line in Figure 9 and the conversion vs. residence time curve shows the significant slowdown in conversion rate that is expected as $X_{c h}$ nears unity. Next the results from the current reactor model are shown by the alternating dot dash line in Figure 9. The results from incorporating the new kinetics model into the old FBG model structure differ from the results obtained from the current FBG model, despite both using the HRPM for gasification kinetics, due to the assumption in the previous model that the char conversion time is equal to the char residence time $\left(\tau=\tau_{R}\right)$. In the current model the char conversion time and the char residence time are related through Equation 15.

Modeling of a pilot scale FBG was also conducted. The pilot scale tests were conducted using coal, peat and pine sawdust fuels at atmospheric and pressurized conditions [20]. For this modeling work only tests using pine sawdust were considered. The details of the pilot plant operation are shown in Table 5. In all tests bottom ash was not removed, and so $1 / \tau_{2}=0$. While fly ash was removed during the tests the removal rate was not measured and so was estimated for modeling purposes. The rate of entrainment of fly ash, $1 / \tau_{3}$, can be calculated by implementing an entrainment submodel as described by Gómez-Barea and Leckner [18], however in this work such a submodel has not been applied. Instead $\tau_{3}$ was indirectly estimated from measurements by assuming all fuel ash, unconverted carbon and added bed material went to fly ash. The carbon conversion, fuel

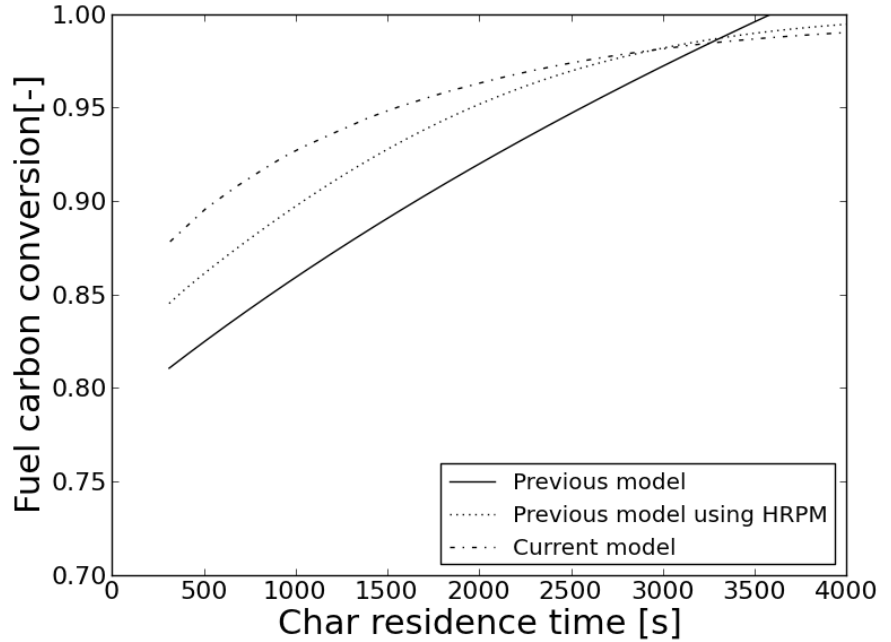

Figure 9: Modeling results from the carbon conversion predictor showing carbon conversion as a function of char residence time in the reactor at $780^{\circ} \mathrm{C}$ for three models: the model as reported by Konttinen et. al [9], the model as reported by Konttinen et. al but using the HRPM, and the current model described in Section 2.4.

ash and added bed material were reported for the pilot plant tests which were simulated (see Table 5) so the flowrate of fly ash was estimated from measured parameters. From these data, the char residence time, $\tau$, can be estimated which corresponds to a given value of $\tau_{3}$.

Table 5: Operating conditions for pilot scale tests using pine sawdust (SD)[20], corresponding to modeling results.

\begin{tabular}{lll}
\hline & Test A & Test B \\
\hline Fuel & Pine SD & Pine SD \\
Bed temperature, ${ }^{\circ} \mathrm{C}$ & 780 & 840 \\
Bed additive & Dolomite & Sand \\
Bed additive rate, g/s & 0.44 & 0 \\
Fuel feed rate, g/s & 12.8 & 9.7 \\
Steam feed, g/s & 2.0 & 2.5 \\
Bottom ash discharge, g/s & 0 & 0 \\
Estimated bed inventory, kg & 12.7 & 12.7 \\
Estimated fly ash discharge, g/s & 0.8 & 0.2 \\
\hline
\end{tabular}

The predicted carbon conversion and product gas composition from both the current reactor model and the previously published version of the model are compared to the measured values in Table 6 . The results show reasonable agreement with the experimental data. Prediction of carbon conversion has improved significantly due to the improved char conversion model. The error in the char conversion prediction at $780^{\circ} \mathrm{C}$ is noticeably larger than $840^{\circ} \mathrm{C}$ which may be due to the addition of dolomite in the lower temperature test and to uncertainties in the experimental measurement leading to over reporting of the carbon conversion. While the differences in experimental setups can make comparison of results tenuous, fluidized bed gasification tests performed by others using pine sawdust gen- 
Table 6: Measurements of carbon conversion and product gas composition of pine sawdust at $780^{\circ} \mathrm{C}$ and $840^{\circ} \mathrm{C}$ [20] compared with the results from the carbon conversion predictor model. The error values reported in the table are the absolute error. * Methane production in the model is calculated using an empirical adjustment factor where $15 \%$ of volatile carbon is assumed to form $\mathrm{CH}_{4}$, corresponding to $78 \mathrm{~g} / \mathrm{kgdaf}$.

\begin{tabular}{|c|c|c|c|c|c|c|}
\hline & \multicolumn{3}{|c|}{$780^{\circ} \mathrm{C}$} & \multicolumn{3}{|c|}{$840^{\circ} \mathrm{C}$} \\
\hline & Measured & Current model & Previous model & Measured & Current model & Previous model \\
\hline Carbon conversion & 95.9 & 89.2 & 81.0 & 97.8 & 98.6 & 100 \\
\hline \multicolumn{7}{|l|}{ Dry gas composition (vol \%) } \\
\hline $\mathrm{N}_{2}$ & 53.0 & 50.3 & 53.2 & 58.0 & 54.4 & 52.3 \\
\hline $\mathrm{H}_{2}$ & 10.9 & 15.2 & 13.6 & 8.4 & 13.0 & 14.2 \\
\hline $\mathrm{CO}_{2}$ & 15.7 & 16.3 & 17.7 & 15.1 & 16.5 & 15.4 \\
\hline $\mathrm{CO}$ & 14.2 & 13.7 & 10.8 & 14 & 12.3 & 14.3 \\
\hline $\mathrm{CH}_{4} *$ & 5.7 & 4.4 & 4.7 & 4.1 & 3.8 & 3.7 \\
\hline $\mathrm{H}_{2} \mathrm{O}$ (wet gas) & 13.8 & 13.5 & 16.1 & 19.1 & 15.6 & 13.8 \\
\hline Average |error| in gas composit & ion & $12.9 \%$ & $15.9 \%$ & & $17.8 \%$ & $20.2 \%$ \\
\hline
\end{tabular}

erally report reaching lower carbon conversion at temperatures around $780^{\circ} \mathrm{C}[21][22]$ than what is measured in the pilot tests used in this work.

The average error in the product gas composition also decreased in the current model. The error in the gas composition model results increases with temperature but the temperature dependent trends in the gas composition are correct with the exception of $\mathrm{CO}_{2}$. Hydrogen content of the product gas is overestimated by the model at both temperatures and has the largest error of the product gas components. Overestimation of hydrogen formation in biomass gasification is common to equilibrium models and has been noted elsewhere [23][24][25]. As this model adjusts the product gas composition according to the equilibrium of the water-gas shift reaction this could contribute to the overestimation of $\mathrm{H}_{2}$ and $\mathrm{CO}_{2}$ in the final gas composition. Published work indicates that it is unlikely that water-gas shift reaction equilibrium is achieved at either $780^{\circ} \mathrm{C}$ or $840^{\circ} \mathrm{C}$ [2] and so this simplification of the model limits the accuracy of the product gas composition estimation.

\section{Conclusion}

A method for modeling char reactivity of pine sawdust measured in TGA experiments has been presented. Based on the TGA measurements for sawdust a catalytic gasification with deactivation of the catalyst stage was observed at low char conversion. By combining the three parallel reaction model with the random pore model, significant improvement in estimated char conversion times was achieved. This reactivity model showed good ability to predict the measured char conversion times and was used to model a pilot scale fluidized bed gasifier. An existing carbon conversion predictor model for fluidized bed gasification of biomass was updated to include the newly developed char gasification kinetic expression and submodel for estimation of char conversion and residence time. The results of the model show improved ability to estimate measured carbon conversion and product gas composition of pine sawdust in a pilot scale fluidized bed gasifier. The FBG model cannot currently be used to completely predict gasifier behavior because some measurements are required to estimate the entrainment of char from the gasifier. Developing an entrainment submodel is required to address this issue.

\section{Acknowledgment}

Financial support for this work from the Academy of Finland through the GASIFREAC project is gratefully acknowledged.

\section{References}

[1] C. Baskar, S. Baskar, R. S. Dhillon (Eds.), Biomass Conversion, Springer, 2012.

[2] A. Gómez-Barea, B. Leckner, Modeling of biomass gasification in fluidized bed, Progress in Energy and Combustion Science 36 (4) (2010) 444-509. doi:10.1016/j.pecs.2009.12.002.

[3] A. Moilanen, Thermogravimetric characterisations of biomass and waste for gasification processes, Ph.D. thesis, Åbo Akademi (2006).

[4] A. Moilanen, K. Saviharju, Gasification reactivities of biomass fuels in pressurised conditions and product gas mixtures, in: A. V. Bridgwater, D. G. B. Boocock (Eds.), Developments in Thermochemical Biomass Conversion, Blackie Academic and Professional, London, 1997, pp. 828837.

[5] K. Umeki, A. Moilanen, A. Gómez-Barea, J. Konttinen, A model of biomass char gasification describing the change in catalytic activity of ash, Chemical Engineering Journal 207-208 (2012) 616-624. doi:10.1016/j.cej.2012.07.025

[6] C. Di Blasi, Combustion and gasification rates of lignocellulosic chars, Progress in Energy and Combustion Science 35 (2) (2009) 121-140. doi:10.1016/j.pecs.2008.08.001

[7] S. Katta, D. L. Keairns, Study of kinetics of carbon gasification reactions, Industrial \& Engineering Chemistry Fundamentals 20 (1) (1981) 6-13. doi:10.1021/i100001a002

[8] W. Klose, M. Wolki, On the intrinsic reaction rate of biomass char gasification with carbon dioxide and steam, Fuel 84 (7-8) (2005) 885-892. doi:10.1016/j.fuel.2004.11.016.

[9] J. T. Konttinen, A. Moilanen, N. DeMartini, M. Hupa, Carbon conversion predictor for fluidized bed gasification of biomass fuels-from TGA measurements to char gasification particle model, Biomass Conversion and Biorefinery 2 (3) (2012) 265-274. doi:10.1007/s13399-012-0038-2.

[10] M. Barrio, Experimental investigation of small-scale gasification of woody biomass, Ph.D. thesis, Norwegian University of Science and Technology (2002). 
[11] D. D. P. S. K. Bhatia, A random pore model for fluid-solid reactions: I. Isothermal, kinetic control, AIChE Journal 26 (3) (1980) 379-386.

[12] D. D. P. S. K. Bhatia, A random pore model for fluid-solid reactions: II Diffusion and transport effects, AIChE Journal 27 (2) (1981) 247-254.

[13] Y. Zhang, M. Ashizawa, S. Kajitani, K. Miura, Proposal of a semi-empirical kinetic model to reconcile with gasification reactivity profiles of biomass chars, Fuel 87 (4-5) (2008) 475-481. doi:10.1016/j.fuel.2007.04.026.

[14] D. Kunii, O. Levenspiel, Fluidization Engineering, ButterworthHeinermann, 1990.

[15] Y. Okumura, T. Hanaoka, K. Sakanishi, Effect of pyrolysis conditions on gasification reactivity of woody biomass-derived char, Proceedings of the Combustion Institute 32 (2) (2009) 2013-2020. doi:10.1016/j.proci.2008.06.024.

[16] E. Cetin, B. Moghtaderi, R. Gupta, T. Wall, Influence of pyrolysis conditions on the structure and gasification reactivity of biomass chars, Fuel 83 (16) (2004) 2139-2150. doi:10.1016/j.fuel.2004.05.008.

[17] J. Konttinen, A. Moilanen, M. Hupa, E. Kurkela, Carbon conversion predictor for fluidized bed gasification of biomass fuels-model concept, in: Science in thermal and chemical biomass conversion, 2006, pp. 590-604.

[18] A. Gómez-Barea, B. Leckner, Estimation of gas composition and char conversion in a fluidized bed biomass gasifier, Fuel (2012) 2022doi:10.1016/j.fuel.2012.09.084.

[19] N. Jand, V. Brandani, P. U. Foscolo, Thermodynamic Limits and Actual Product Yields and Compositions in Biomass Gasification Processes, Industrial \& Engineering Chemistry Research 45 (2) (2006) 834-843. doi:10.1021/ie050824v.

[20] E. Kurkela, P. Stå hlberg, J. Laatikainen-Luntama, Pressurized fluidizedbed gasification experiments with wood, peat and coal at VTT in 19911994. Part 2. Experiences from peat and coal gasification and hot gas filtration, VTT Publications, 1994.

[21] J. Herguido, J. Corella, J. Gonzalez-Saiz, Steam gasification of lignocellulosic residues in a fluidized bed at a small pilot scale. Effect of the type of feedstock, Industrial \& Engineering Chemistry Research 31 (5) (1992) 1274-1282. doi:10.1021/ie00005a006.

[22] P. M. Lv, Z. H. Xiong, J. Chang, C. Z. Wu, Y. Chen, J. X. Zhu, An experimental study on biomass air-steam gasification in a fluidized bed., Bioresource technology 95 (1) (2004) 95-101. doi:10.1016/j.biortech.2004.02.003.

[23] M. Puig-Arnavat, J. C. Bruno, A. Coronas, Review and analysis of biomass gasification models, Renewable and Sustainable Energy Reviews 14 (9) (2010) 2841-2851. doi:10.1016/j.rser.2010.07.030.

[24] X. Li, J. Grace, C. Lim, a.P. Watkinson, H. Chen, J. Kim, Biomass gasification in a circulating fluidized bed, Biomass and Bioenergy 26 (2) (2004) 171-193. doi:10.1016/S0961-9534(03)00084-9.

[25] M. Ruggiero, G. Manfrida, An equilibrium model for biomass gasification processes, Renewable energy. 